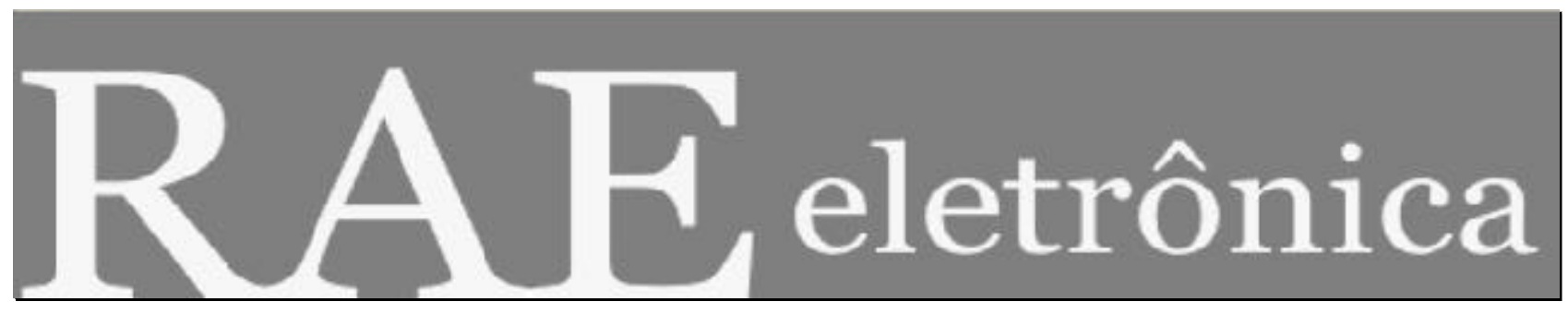

FÓRUM - SOCIOLOGIA ECONÔMICA

FORO - SOCIOLOGÍA ECONÓMICA

FORUM - ECONOMIC SOCIOLOGY

\title{
ATUALIDADE DA CONSTRUÇÃO DO OBJETO CIENTÍFICO DA SOCIOLOGIA ECONÔMICA
}

ACTUALIDAD DE LA CONSTRUCCIÓN DEL OBJETO CIENTÍFICO DE SOCIOLOGÍA ECONÓMICA

THE PRESENT TIME OF THE CONSTRUCTION OF THE SCIENTIFIC OBJECT OF ECONOMIC SOCIOLOGY

Por:

JOSÉ MARIA CARVALHO FERREIRA, UNIVERSIDADE TÉCNICA DE LISBOA.

RAE-eletrônica, v. 6, n. 1, Art. 8, jan./jun. 2007

http://www.rae.com.br/eletronica/index.cfm?FuseAction=Artigo\&ID=4036\&Secao=FÓRUM\&Volume $=6 \&$ numero $=1 \& A$ no $=2007$

CCopyright, 2007, RAE-eletrônica. Todos os direitos, inclusive de tradução, são reservados. É permitido citar parte de artigos sem autorização prévia desde que seja identificada a fonte. A reprodução total de artigos é proibida. Os artigos só devem ser usados para uso pessoal e nãocomercial. Em caso de dúvidas, consulte a redação: raeredacao@fgvsp.br.

A RAE-eletrônica é a revista on-line da FGV-EAESP, totalmente aberta e criada com o objetivo de agilizar a veiculação de trabalhos inéditos. Lançada em janeiro de 2002, com perfil acadêmico, é dedicada a professores, pesquisadores e estudantes. Para mais informações consulte o site www.rae.com.br/eletronica.

RAE-eletrônica

ISSN 1676-5648

(C2007 Fundação Getulio Vargas - Escola de Administração

de Empresas de São Paulo.

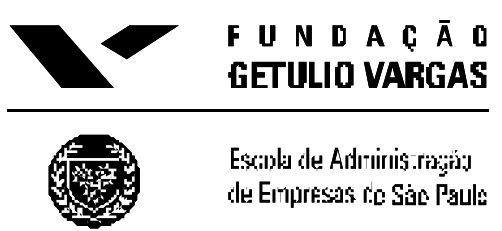




\section{FÓRUM - SOCIOLOGIA ECONÔMICA \\ ATUALIDADE DA CONSTRUÇÃO DO OBJETO CIENTÍFICO DA SOCIOLOGIA ECONÔMICA \\ José Maria Carvalho Ferreira}

\section{RESUMO}

A emergência científica da sociologia econômica é, hoje, um tema relevante nas ciências sociais. A articulação entre os domínios sociais e econômicos é visível na produção, distribuição, troca e consumo de bens e serviços imateriais. Com base em uma leitura documental de autores e paradigmas, este artigo contrasta e compara as profundas mudanças sociais e econômicas que atravessam a organização do trabalho e o terceiro setor. Como resultado, observamos mudanças em nível da divisão do trabalho, da autoridade hierárquica formal, nos processos de decisão e de liderança nas organizações e instituições da sociedade civil. Adicionalmente, as novas tecnologias e a globalização representada pelas ações das transnacionais e das multinacionais provocaram uma crise do Estado-Nação. É nesse contexto que propomos uma reflexão sobre o objeto da sociologia econô mica na atualidade.

\section{PALAVRAS-CHAVE}

Sociologia econômica; divisão do trabalho; autoridade hierárquica formal; tomada de decisão; liderança.

\section{ABSTRACT}

The scientific uprising of de economic sociology is, nowadays, a relevant theme within the sociological sciences. The articulation between the sociological and the economical domains becomes visible mainly in the production, distribution, exchange and consummation of immaterial goods and services. Based on some authors' documental reading and on paradigms' analyses it was possible to compare and contrast the deep social and economical changes which cross, both the work's organization and the third setor. As a whole, we can recognize changes on what concerns the work's division, the formal hierarchical authority, the process of decision making and leadership in the organizations and institutions of the civil society. But we also can observe how the new technologies and the globalization, through the trans-national and multinational enterprises cause such a stroke in StateNation. Considering this context, we are handling with an observation object that enormously increases the contemporaneous hypothesis of the object of the economical sociology.

\section{KEYWORDS}

Economical sociology; work's division; formal hierarchical authority; decision making; leadership. 


\section{FÓRUM - SOCIOLOGIA ECONÔMICA \\ ATUALIDADE DA CONSTRUÇÃO DO OBJETO CIENTÍFICO DA SOCIOLOGIA ECONÔMICA \\ José Maria Carvalho Ferreira}

\section{INTRODUÇÃO}

Os desafios epistemológicos e metodológicos envolvidos com a construção do objeto científico da sociologia econômica são extremamente complexos, não obstante esta área do conhecimento ter conhecido um grande desenvolvimento nas últimas décadas do século XX.

Em primeiro lugar, os problemas epistemológicos relacionados às dificuldades históricas de delimitação das fronteiras do objeto científico da sociologia econômica têm sido tema de debates pouco profícuos entre sociólogos e economistas, os quais, até o momento, não têm revertido em um diálogo consistente e sistemático (Swedberg, 1994; Steiner, 1999). Em segundo lugar, a institucionalização progressiva da sociologia, como ciência social no contexto da sociedade e do mercado, tem-se traduzido na sua fragmentação científica, levando à proliferação de uma série de disciplinas especializadas. Nesse contexto, a procura por uma identidade científica tem gerado a concorrência e a competição, não só entre sociólogos e economistas, mas sobretudo entre os sociólogos das diferentes especialidades científicas.

A sociologia econômica não é exceção a essa regra, na medida em que, como objeto científico generalista de natureza socioeconômica, recorre a uma série de abordagens centradas no mercado de trabalho, na teoria das redes e na teoria das organizações, recorrendo a postulados sociológicos que integram o institucionalismo, a cultura, a antropologia e a história. Em terceiro lugar, os problemas de integração e de síntese conceitual persistem, na medida em que o objeto científico da sociologia econômica é o resultado intrínseco de diferentes leituras e interpretações, confinadas ao mesmo objeto de observação.

Nesse contexto, o principal objetivo deste artigo é discutir alguns elementos para a construção do objeto científico da sociologia econômica. Para tanto, toma-se aqui como referência o tema da organização do trabalho e do terceiro setor nas sociedades contemporâneas. Em específico, o artigo parte do princípio de que a sociologia econômica, enquanto objeto científico dotado de conteúdos singulares e de fronteiras próprias, pode ser definida como a ciência que estuda "as atividades econômicas de produção, distribuição, troca e consumo de bens e serviços incrustados em estruturas sociais e relações sociais" (Durkheim, 1991; Weber, 1944; Polanyi, 1989; Granovetter, 1985; Lèvesque, 2001). Enquanto partes integrantes da sociedade global, a organização do trabalho e o terceiro setor são alvos de observação dos quais decorre o objeto científico da sociologia econômica, 


\section{FÓRUM - SOCIOLOGIA ECONÔMICA \\ ATUALIDADE DA CONSTRUÇÃO DO OBJETO CIENTÍFICO DA SOCIOLOGIA ECONÔMICA \\ José Maria Carvalho Ferreira}

cuja análise e estudo empírico passarão aqui por uma abordagem microssociológica e macrossociológica.

O artigo está estruturado da seguinte forma. Em primeiro lugar, discute-se a organização do trabalho no quadro da racionalidade instrumental do capitalismo, especificando as modalidades de racionalização do fator de produção trabalho, que estruturam e viabilizam a maximização do lucro. Os conceitos centrais em foco são a divisão do trabalho, a autoridade herárquica formal, o processo de tomada de decisão e o processo de liderança, os quais constituem as estruturas sociais e as relações sociais da organização do trabalho, dando forma às múltiplas organizações das sociedades contemporâneas mais desenvolvidas.

Em segundo lugar, após ter demonstrado as limitações e as contradições resultantes da atual organização do trabalho, quer em termos normativos da regulação do mercado quanto do Estado, são analisadas as variáveis macrossociológicas envolvidas na socialização do fator de produção trabalho, especificamente as mudanças relacionadas com as qualificações e competências, com o emprego, o desemprego, a precariedade da vinculação contratual de trabalho e a exclusão social.

Por último, o artigo dedica-se à análise da emergência do terceiro setor nas sociedades contemporâneas. Para realizar essa análise, investiga a dupla natureza desse setor e acompanha suas evoluções histórias - as quais, embora diferentes nos seus conteúdos e formas econômicas, sociais, políticas e culturais, são complementares e interdependentes.

De um lado, o terceiro setor é um campo de atividade econômica que procura adaptar-se e reagir às pressões da concorrência e da competição, geradas pela regulação do Estado, do mercado, da economia informal e da economia doméstica. De outro, é um setor que procurou, historicamente, constituir-se como uma alternativa ao Estado e ao mercado e que, hoje, procura novamente reconstruir essa missão, impulsionado que é pelas mudanças profundas em nível da orga nização do trabalho, da produção, da distribuição, da troca e do consumo de bens e serviços com características imateriais.

\section{Organização do trabalho}

Em quase todos os países do mundo, particularmente aqueles que já foram objeto de um crescimento e desenvolvimento econômico significativos, observa-se que a realidade da organização do trabalho é atravessada, inexoravelmente, por profundas mudanças, no que diz respeito à divisão do trabalho, à estrutura hierárquica de autoridade formal, ao processo de tomada de decisão e ao processo de liderança. 


\section{FÓRUM - SOCIOLOGIA ECONÔMICA \\ ATUALIDADE DA CONSTRUÇÃO DO OBJETO CIENTÍFICO DA SOCIOLOGIA ECONÔMICA \\ José Maria Carvalho Ferreira}

O carácter tendencial dessa evolução e, sobretudo, os contornos e os conteúdos das mudanças que envolvem a organização do trabalho no contexto da racionalidade instrumental do capitalismo nos levam a privilegiar uma análise centrada na União Européia e em outros países capitalistas mais desenvolvidos.

Quando nos referimos à energia, informação e conhecimento humanos, estamos pensando em todo tipo de interações que se estabelecem entre as novas tecnologias e o fator de produção trabalho. Pensamos nos domínios do "saber fazer", das qualificações e das competências e, logicamente, pensamos nos gestos, movimentos, pausas e tempos do fator de produção trabalho, todos imprescindíveis para a produção de qualquer bem ou serviço.

De fato, em todos esses domínios o desenvolvimento da automatização, gerado pelas novas tecnologias, tem-se traduzido, simultaneamente, em um desvio progressivo da energia, da informação e do conhecimento humanos (anteriormente integrados nas funções etarefas executadas pelo fator de produção trabalho) para os mecanismos automáticos das novas tecnologias. O processo de automatização desenvolvido pelas novas tecnologias, ainda que seja criador de novas qualificações e competências, elimina, de uma forma inexorável, a autonomia e o papel relevante que o trabalhador detinha no contexto do modelo de produção e consumo em massa de tipo fordista (Cavestro, 1984).

Essa evolução do processo de trabalho no sentido da automatização obriga a uma adaptação sistemática do fator de produção trabalho em termos de um novo "saber fazer", expresso na exigência de novas competências, novas qualificações, novos ritmos, novos gestos, novas pausas, novos tempos e movimentos e, necessariamente, novas capacidades cognitivas, emocionais e comportamentais. São exigências de tipo físico, afetivo e comunicacional, sendo que, em relação a estas últimas, se assiste a um aumento exponencial, quer em termos quantitativos quer qualitativos.

Essa adaptação desenvolve-se na lógica da concorrência e da competição no mercado interno da organização do trabalho, sempre pautada por uma crescente necessidade de aumento de produtividade do fator de produção trabalho. Na lógica do management, ou seja, dos imperativos da gestão no atual contexto da racionalidade instrumental do capitalismo, a flexibilidade, a polivalência e a empregabilidade são os fatores em "moda" mais visíveis da inovação e da mudança que se pretendem realizar no âmbito da organização do trabalho.

Este processo não é, todavia, linear. A adaptação e a reação do fator de produção trabalho às pressões dos mecanismos automáticos das novas tecnologias não são, por si só, sinônimo de eficiência ou de eficácia. Admitindo que as novas tecnologias são a personificação da crescente integração e racionalização, dinamizadas pela ciência e a pela técnica, não é menos verdade que as restrições 


\section{FÓRUM - SOCIOLOGIA ECONÔMICA \\ ATUALIDADE DA CONSTRUÇÃO DO OBJETO CIENTÍFICO DA SOCIOLOGIA ECONÔMICA}

José Maria Carvalho Ferreira

estruturais e institucionais da racionalização da organização do trabalho se desenvolvem no mesmo sentido: quer em relação aos processos de tomada de decisão e de liderança, quer em relação à estrutura hierárquica da autoridade formal e às tarefas envolvidas na divisão do trabalho (Ferreira, 2001).

A divisão do trabalho, como elemento estrutural e institucional da organização do trabalho, determina de modo prescritivo o papel de cada trabalhador na execução de tarefas, ou funções que implicam qualificações e competências específicas. As interdependências e as complementaridades resultantes das restrições institucionais e estruturais determinam, em última instância, a emergência do processo de produção de bens e serviços envolvidos em relações sociais e relações interpessoais de tipo formal e informal.

Associando a influência das novas tecnologias ao aumento da capacidade de socialização da energia, da informação e da comunicação no espaço-tempo confinado ao processo de trabalho, a divisão do trabalho desenvolve-se no sentido da sua extensão e intensidade automática. A divisibilidade e a especialização das tarefas e funções são objeto de uma maior plasticidade social, exibindo uma maior coincidência entre o tempo real e o tempo virtual. O papel do fator de produção trabalho é, por tais motivos, potenciado, quer em termos das suas qualificações e competências, quer em termos da sua autonomia e intervenção espaço-temporal. Para se adequar aos requisitos da emissão, transmissão e recepção da informação, conhecimento e energia que estipulam os papéis circunscritos à execução de uma dada tarefa ou função, só com uma divisão do trabalho identificada com a polivalência, a flexibilidade e a empregabilidade do fator de produção trabalho é possível que este atinja o máximo de produtividade de bens e serviços.

As pressões estruturais e institucionais que decorrem da divisão do trabalho não implicam exclusivamente o aumento da produtividade do trabalho e da especialização na execução de tarefas relacionadas com a produção de bens e serviços. A racionalidade instrumental do capitalismo, assim como as mudanças e as inovações operadas pelas novas tecnologias na organização do trabalho, atravessam o espaço-tempo da distribuição, da troca e do consumo de bens e serviços. As exigências de concorrência e de competitividade entre as múltiplas organizações no âmbito local, regional, nacional e mundial têm-se traduzido em um incremento da especialização e da atomização das funções e tarefas restritas à gestão, à programação, à coordenação e controle do processo de trabalho, gerando, por conseqüência, um desenvolvimento da divisão do trabalho (Pottier, 1998).

Existem, no entanto, tendências contrárias ao desenvolvimento da divisão do trabalho, especificamente aquelas que estão ligadas às capacidades e aos limites de ação cognitiva, emocional e comportamental do fator de produção trabalho. Esses aspectos podem ser facilmente reconhecidos ao 


\section{FÓRUM - SOCIOLOGIA ECONÔMICA \\ ATUALIDADE DA CONSTRUÇÃO DO OBJETO CIENTÍFICO DA SOCIOLOGIA ECONÔMICA \\ José Maria Carvalho Ferreira}

observarmos a natureza e os imperativos espaço-temporais da socialização da informação, do conhecimento e da energia no processo de trabalho. O tempo real aproxima-se ou coincide cada vez mais do tempo virtual; em relação ao acesso, regulação e controle da informação, conhecimento e energia são necessários para a execução de tarefas e funções. Por outro lado, devido à sua crescente automatização, esses fatores foram substancialmente diminuídos em relação aos tempos de emissão, transmissão e recepção m sentido horizontal e vertical. Como consequiência, torna-se crucial eliminar todos os obstáculos ou condicionamentos que possam provocar ruídos, enviesamentos ou conflitos entre indivíduos ou entre grupos que integram os processos de tomada de decisão e de liderança e, logicamente, o processo de trabalho.

A tendência para um aumento da qualificação ou da desqualificação do fator de produção trabalho observa-se no contexto da racionalização da organização do trabalho e da divisão do trabalho que lhe é subjacente. Nos setores em que as funções e as tarefas exigem competências e qualificações de programação, concepção e manutenção inerentes às novas tecnologias, a tendência é para um aumento significativo da qualificação do fator de produção trabalho e, logicamente, da divisão do trabalho, em termos quantitativos e qualitativos. Todavia, em uma situação oposta, as tarefas e funções que exigem poucas competências e qualificações, que estimulam comportamentos, afetos e atividades cognitivas reduzidas e exigem, exclusivamente, esforço físico, evoluem no sentido da desqualificação do fator de produção trabalho e da extinção de postos de trabalho (Brock e Vetter, 1986).

A autoridade hierárquica formal é um elemento estrutural e institucional da organização do trabalho que determina, de modo prescritivo, as modalidades de coordenação e de controle do processo de trabalho, ou seja, aquelas que emergem no processo de produção de bens e serviços, pertencentes a relações sociais e a relações interpessoais que configuram a socialização do poder e os fluxos de autoridade no sentido vertical. As novas tecnologias não se coadunam com o caráter prescritivo da autoridade hierárquica formal. Esta revela-se demasiadamente rígida em relação às exigências da socialização da informação, do conhecimento e da energia que emergem das necessidades comunicacionais e afetivas dos atores no processo de trabalho no momento da realização das tarefas e funções.

A descentralização e a participação dos múltiplos atores que intervêm nesse processo impõemse sobremaneira entre os diferentes níveis hierárquicos de autoridade formal, nas relações interpessoais entre chefes e subordinados e, também, entre grupos no que respeita às relações intragrupais e intergrupais. A coordenação e o controle da autoridade hierárquica colidem com um tipo de "democracia direta" imposta pelas novas tecnologias na organização do trabalho. Assim, para que o 


\section{FÓRUM - SOCIOLOGIA ECONÔMICA \\ ATUALIDADE DA CONSTRUÇÃO DO OBJETO CIENTÍFICO DA SOCIOLOGIA ECONÔMICA \\ José Maria Carvalho Ferreira}

fator de produção trabalho se torne, efetivamente, eficiente, para que a emissão, a transmissão e a recepção da informação, o conhecimento e a energia - relacionados com a produção de bens e serviços - sejam, objetivamente, realizados, é imperativo que a autoridade hierárquica permita a socialização necessária e esperada desses múltiplos fatores no sentido descendente, ascendente e horizontal.

Devido à persistência de efeitos perversos nesse processo, não admira que muitas empresas e outras organizações, para se tornarem eficientes e competitivas, eliminem alguns níveis intermediários da estrutura hierárquica da autoridade formal e, logicamente, extingam tarefas e funções que antes estavam confinadas ao controle e à coordenação das relações sociais e relações interpessoais que manifestamente condicionavam e condicionam a plasticidade social da comunicação e dos afetos que emergem no processo de trabalho. Nesse sentido, para que a socialização da informação, do conhecimento e da energia se realize no sentido vertical e horizontal, é fundamental evoluir no sentido do achatamento da pirâmide hierárquica das múltiplas organizações e, simultaneamente, no sentido da extinção de postos de trabalho (Meda, 1995).

As contingências das novas tecnologias e da organização do trabalho em relação aos processos de tomada de decisão e de liderança têm múltiplas vertentes. O processo de tomada de decisão, enquanto elemento estrutural e institucional da organização do trabalho, determina o processo de produção de bens e serviços incrustados nas relações sociais e relações interpessoais, as quais definem as modalidades de participação e de socialização da informação, do conhecimento e da energia mobilizados pelos atores individuais e coletivos. Em uma situação de complementaridade e de interdependência, o processo de liderança, como elemento estrutural e institucional da organização do trabalho, está articulado com a produção de bens e serviços incrustados em relações interpessoais e relações sociais que dinamizam a influência social no processo de trabalho.

No caso específico do processo de tomada de decisão, para que a transmissão de informação, do conhecimento e da energia seja realizada de forma adequada e esperada, é necessário que as relações sociais sejam estruturadas por um tipo de participação e de "democracia direta", de modo que possam emergir espontânea e informalmente, subtraindo-se e adaptando-se às pressões e perversões da estrutura hierárquica da autoridade formal. Quanto maiores são os níveis da autoridade hierárquica formal, maior é a dificuldade de apropriação, de regulação e socialização inerente ao processo de transformação de inputs em outputs.

Por outro lado, as linguagens das novas tecnologias implicam a descodificação e a codificação de novos signos e significados. Os atores, que necessitam de informação e conhecimento para executarem as suas tarefas e funções, são pressionados a desenvolver adequadamente as suas 


\section{FÓRUM - SOCIOLOGIA ECONÔMICA \\ ATUALIDADE DA CONSTRUÇÃO DO OBJETO CIENTÍFICO DA SOCIOLOGIA ECONÔMICA \\ José Maria Carvalho Ferreira}

capacidades de emissão e recepção de informação quando estão em uma situação de interação, permitindo assim que a transmissão da informação, que atravessa o funcionamento das organizações, seja efetivamente realizada.

Nas sociedades capitalistas desenvolvidas, as organizações e instituições são bombardeadas por uma quantidade gigantesca e complexa de informações, cuja socialização é extremamente difícil de realizar, sobretudo quando emerge em um ambiente repleto de incerteza e risco. Além disso, essa socialização está sujeita aos condicionamentos temporais, psíquicos e mentais e físicos que decorrem da execução de tarefas e funções. Por isso, hoje, desde o início ao fim de qualquer processo de tomada de decisão, não basta organizar e categorizar a informação que é necessária para iniciar esse processo na generalidade dos casos, na ausência dessa informação substantiva, muitas organizações e instituições limitam-se a desenvolver o processo de tomada de decisão de forma rotineira, colocando em risco a própria sobrevivência da organização.

A solução dos problemas no processo de tomada de decisão é de natureza muito difícil devido à complexidade desses problemas. É imperativo, em primeiro lugar, organizar e categorizar um tipo de informação composta por signos e significados primacialmente abstratos e imateriais. Em segundo lugar, os atores, para participarem efetivamente no processo de tomada de decisão, têm que adquirir valências comunicacionais, através da aprendizagem social e da formação, que lhes permitam adquirir o conhecimento imprescindível. Este revela-se fundamental em termos das qualificações e competências que são essenciais para executar as tarefas e funções de forma proficiente (Goldfinger, 1998; Rose, 1998).

Embora possamos afirmar que as contingências das inovações e das mudanças provocadas pelas novas tecnologias na organização do trabalho não sejam tão visíveis no processo de liderança, como já foi referido em relação ao processo de tomada de decisão, o seu impacto é, no entanto, significativo no comportamento dos líderes e dos membros das organizações que são influenciados pelas suas ações no processo de produção de bens e serviços. Na estrita medida em que a socialização da informação, do conhecimento e da energia atravessa todas as relações sociais em que está presente a autoridade hierárquica e, consequientemente, o exercício do poder, as exigências de maior participação e de descentralização na execução de tarefas e funções implicam que as relações nterpessoais entre os líderes e o seus subordinados sejam, em muitos casos, de tipo informal e espontâneo.

Todavia, as pressões estruturais e funcionais da organização do trabalho legitimam o desenvolvimento de um tipo de liderança formal. Mas, perante a contingência da implementação da polivalência e da flexibilidade, assim como da própria empregabilidade, no contexto da organização do 


\section{FÓRUM - SOCIOLOGIA ECONÔMICA \\ ATUALIDADE DA CONSTRUÇÃO DO OBJETO CIENTÍFICO DA SOCIOLOGIA ECONÔMICA \\ José Maria Carvalho Ferreira}

trabalho, os líderes, para serem efetivamente eficientes, necessitam não apenas de prerrogativas de carácter formal, como também de valências comunicacionais e afetivas, que viabilizem as relações sociais e as relações interpessoais de tipo informal e espontâneo. Por outro lado, para se criarem empatias e sociabilidades positivas entre os líderes e os liderados, estes últimos necessitam de uma margem de manobra, de responsabilidade e criatividade que lhes permita desenvolver relações sociais e relações interpessoais de tipo informal e espontâneo.

\section{Dualizações do mercado de trabalho}

Entre as conseqüências mais representativas das mudanças operadas pelas novas tecnologias na organização do trabalho, a mais importante refere-se às mudanças nas qualificações e competências do fator de produção trabalho, especificamente no que concerne às reestruturações dos perfis socioprofissiona is (Dubar, 1998). Essas reestruturações têm implicações profundas na evolução do desemprego, da precariedade dos vínculos contratuais e da exclusão social. Ainda que não possamos arbitrariamente raciocinar em termos de uma evolução linear, mas de uma evolução multilinear, com base na maioria dos analistas, podemos destacar as principais dualidades que acompanham o atual processo histórico dos países capitalistas mais desenvolvidos: 1) aumento da qualificação/ desqualificação; 2) emprego/desemprego; 3) estabilidade da vinculação contratual de trabalho/precariedade da vinculação contratual de trabalho; 4) integração social/exclusão social.

A controvérsia a respeito das tendências e evidências empíricas das competências e das qualificações que dão forma aos perfis socioprofissionais e às exigências de execução de tarefas e funções do fator de produção trabalho geralmente circunscreve-se àqueles que opinam no sentido da sua desqualificação (Braverman, 1977) ou no sentido do aumento da sua qualificação (Kern e Schumann, 1988). Ambas as análises são válidas e pertinentes. Partimos do pressuposto de que para a realização de todas as funções e tarefas, que estão articuladas com os procedimentos técnicos e funcionais das novas tecnologias (nos domínios da programação, concepção, planeamento, gestão, controle e manutenção), são exigidos novos conhecimentos, novos comportamentos de carácter físico e cognitivo, que se consubstanciam num efetivo aumento qualitativo e quantitativo das qualificações e competências do fator de produção trabalho.

A tendência para a desqualificação do fator de produção trabalho traduz-se estruturalmente em um aumento do desemprego (Rifkin, 1996). Emerge, na atualidade, uma segunda tendência de dualização no mercado de trabalho, expressa pela hipótese de o fator de produção trabalho ter emprego ou mergulhar no desemprego. Sozinho, como acabamos de verificar, o processo de automatização do 


\section{FÓRUM - SOCIOLOGIA ECONÔMICA \\ ATUALIDADE DA CONSTRUÇÃO DO OBJETO CIENTÍFICO DA SOCIOLOGIA ECONÔMICA \\ José Maria Carvalho Ferreira}

processo de trabalho gera desemprego. Todavia, importa ainda fazer menção às redes sociais de tipo formal e informal que, entretanto, são estruturadas como procura efetiva de emprego e não conseguem viabilizar esse objetivo. Os exemplos dos milhares de milhões de jovens, mulheres, minorias étnicas e imigrantes que procuram emprego e vêem frustradas as suas ações individuais e coletivas são elucidativos.

Não admira que o contingente de milhões de desempregados e de contratados com vínculos precários não pare de crescer (Grozelier, 1998). Todos os trabalhadores assalariados que estão nessas condições vêem se impedidos não somente de trabalhar em condições normais, mas também de obter rendimentos e outros benefícios sociais, políticos e culturais mínimos (Castel, 1998). Recebendo salários baixos e não usufruindo de uma estabilidade vinculativa no mercado de trabalho, ño admira que, no mundo dos trabalhadores assalariados, milhares sejam remetidos para a base da pirâmide da atual escala de estratificação social e que, por outro lado, tenham poucas ou nenhuma chance de mobilização social no sentido ascendente dessa mesma escala de estratificação social.

Todavia, todos aqueles que, por meio da formação e da educação, possuírem as competências e qualificações requeridas pelas novas tecnologias e as mudanças operadas na organização do trabalho e tenham, entretanto, adquirido valências comportamentais, emocionais e cognitivas traduzíveis em capacidades de competição e de concorrência acrescidas no mercado de trabalho têm probabilidades de integrarem o topo da pirâmide da escala de estratificação social e evoluírem no sentido de uma mobilidade social ascendente.

Desta realidade podemos observar uma terceira dualização no mercado de trabalho: estabilidade da vinculação contratual de trabalho versus precariedade da vinculação contratual de trabalho. Neste caso, todos os que conseguirem usufruir de qualificações e competências adequadas às pressões técnicas, científicas e institucionais requeridas pela evolução da racionalidade instrumental do capitalismo tenderão a integrar o mercado de trabalho com vinculação contratual estável. No sentido contrário, todos aqueles que evoluírem na direcção da desqualificação e do desemprego caminharão, irremediavelmente, para uma situação de instabilidade e de precariedade, integradas nas múltiplas dimensões formais e informais de vinculação contratual do fator de produção trabalho.

Além dessas três dualizações observadas no mercado de trabalho, importa sublinhar uma outra que funciona como síntese delas todas. Os trabalhadores assalariados que consideramos como qualificados, que têm emprego e vinculação contratual de trabalho estável, se continuarem a demonstrar uma grande capacidade de concorrência e de competição no mundo do trabalho assalariado, tornar-se-ão os fomentadores da integração social e da ordem social, política, cultural e econômica. 


\section{FÓRUM - SOCIOLOGIA ECONÔMICA \\ ATUALIDADE DA CONSTRUÇÃO DO OBJETO CIENTÍFICO DA SOCIOLOGIA ECONÔMICA \\ José Maria Carvalho Ferreira}

Contudo, a trajetória temporal previsível dos desqualificados, dos desempregados e dos que têm um vínculo contratual precário caminha no sentido da exclusão social e da marginalidade social. Qualquer uma destas condições não é passível de estruturar a integração social, nem tampouco se identifica com a ordem econômica, social, política e cultural que configuram a racionalidade instrumental do capitalismo. Não admira, assim, que a tendência da exclusão social culmine na produção sistemática do desvio. Os custos do desvio são enormes, sobretudo em termos do aumento drástico dos seus efeitos perversos, corporizados no aumento exponencial do crime, da droga, da violência, da miséria humana e da destruição do planeta Terra.

\section{A emergência histórica do terceiro setor}

A crescente integração da ciência e da técnica no quadro da racionalidade instrumental do capitalismo traduz-se em uma série de pressões estruturais e institucionais, cujas implicações profundas têm originado grandes mudanças nas novas tecnologias, na organização do trabalho e no mercado de trabalho.

Entre os efeitos mais representativos dessas mudanças, tendo em vista o aumento significativo do desemprego e da precariedade da vinculação contratual de trabalho assalariado (Paugam, 2000), podemos citar a crise de legitimidade e de regulação do Estado e do mercado. A comparação com o período histórico dos trinta anos gloriosos do capitalismo (1945-1975) é, nesse caso, elucidativa. O pleno emprego e a generalização de políticas sociais permitiram uma regulação e uma estabilidade da vinculação contratual de trabalho assalariado através da implementação do modelo de produção e de consumo em massa de tipo fordista (Boyer, 1986). Depois do final da década de 1970, as evidências empíricas da crise de regulação e de controle do Estado e do mercado, em relação ao fator de produção trabalho, são de tal modo evidentes que não é possível prever os seus contornos no futuro próximo.

A crise do Estado pode ser visualizada em diferentes dimensões. Em primeiro lugar, no domínio das políticas sociais, na estrita medida em que não têm a capacidade financeira suficiente para investir na saúde, na assistência social, na segurança social, na formação e na educação (Rosanvallon, 1995). Outro aspecto da crise do Estado tem a ver com sua relação com a sociedade civil, enquanto estrutura e instituição de representatividade social e de governança. Na perspectiva de Hobbes, o Estado tinha por função regular e controlar as relações sociais e as relações pessoais da sociedade civil através de um contrato social, cuja incidência espaço-temporal o transformaria em um ser onipotente e onipresente. Hoje, a crise de legitimidade do Estado junto da sociedade civil demonstra o contrário.

No momento atual, em presença de uma crise de regulação e de controle por parte do Estado, 


\section{FÓRUM - SOCIOLOGIA ECONÔMICA \\ ATUALIDADE DA CONSTRUÇÃO DO OBJETO CIENTÍFICO DA SOCIOLOGIA ECONÔMICA \\ José Maria Carvalho Ferreira}

poder-se-ia pensar que o mercado, enquanto entidade natural e abstrata, resolveria facilmente os dilemas e os problemas que afetam a sociedade civil. De fato, a procura, que está direta ou indiretamente ligada com a resolução da imensa quantidade de problemas que afetam a sociedade civil, não tem correspondência na oferta, desenvolvida no âmbito das virtualidades concernentes ao mercado. Seguindo os postulados dos economistas clássicos e neoclássicos, o mercado seria o espaço-tempo de um processo de socialização de trocas sistemáticas, que refletiria, através da procura e da oferta, os interesses, objetivos e estratégias dos produtores e consumidores de bens e serviços. No seu entendimento e explicação, cada indivíduo é soberano e livre para determinar a oferta e a procura, que, por efeitos integradores generalizados, culminaria em um equilíbrio sistemático no mercado.

Estando o Estado e o mercado em crise, e mediante a sua explícita incapacidade de regular e controlar as perversões e os desvios potenciais de milhares de trabalhadores desempregados, de milhares de trabalhadores com vinculação contratual precária, de milhares de excluídos sociais, para todos eles, as hipóteses de sobrevivência que se configuram no horizonte próximo resumem-se a uma escolha de mobilidade social, cujo sentido mais representativo é a integração na economia informal.

A economia informal tende a desenvolver-se de uma forma exponencial nos países capitalistas mais desenvolvidos e menos desenvolvidos, pois está na origem da própria sobrevivência histórica de todos aqueles que mergulharam no desemprego, na precariedade da vinculação contratual e na exclusão social. Na atualidade, só a economia informal pode desenvolver uma dinâmica consistente no mundo do crime, da droga, da violência e da exclusão social através da produção, distribuição, troca e consumo de bens e serviços que lhe são específicos. Por outro lado, existe uma enorme correlação entre a economia informal e a economia formal. Isso acontece devido às interdependências e complementaridades criadas entre elas no que toca às necessidades de produção, distribuição, troca e consumo que estão na base da formação da procura e da oferta do mercado normativo e do mercado paralelo.

Embora seja difícil determinar os contornos do objeto de observação e do objeto científico concernentes ao terceiro setor, é possível delimitá-los, tendo presentes duas dimensões básicas. Primeira, a que decorre da sua historicidade, enquanto modelo alternativo às modalid ades de regulação e de controle desenvolvidas pelo mercado e pelo Estado. Segunda, a que está associada às vicissitudes de adaptação e de reação do terceiro setor à crise de regulação e de controle por parte do Estado e do mercado nas sociedades contemporâneas. Desse modo, o terceiro setor personifica uma evolução histórica integrada, de princípios e práticas, com uma geografia cultural e humana específicas (Costa, 1986; Gide, 1905; Hall, 1987), resultando dos dilemas contemporâneos que a sociedade civil é forçada 


\section{FÓRUM - SOCIOLOGIA ECONÔMICA \\ ATUALIDADE DA CONSTRUÇÃO DO OBJETO CIENTÍFICO DA SOCIOLOGIA ECONÔMICA \\ José Maria Carvalho Ferreira}

a assumir, perante as contingências da crise do Estado e do mercado, nas suas múltiplas dimensões.

Como primeira aproximação conceitual ao terceiro setor, é preciso deduzir que as suas atividades são distintas da economia informal e da economia doméstica (Billiard, Debordeaux e Lurol, 2000; Lallement e Laville, 2002). Não basta dizer que o terceiro setor preenche os requisitos de produção, distribuição, troca e consumo em relação a um tipo de atividades específicas. Importa também que as suas estruturas, os seus objetivos e estratégias organizacionais tenham visibilidade no contexto das sociedades contemporâneas.

Nesse sentido, há alguns princípios comuns geralmente incorporados no regime jurídico e no funcionamento organizacional das associações, mutualidades ou cooperativas que integram o terceiro setor. Primeiro, eles possuem uma estrutura institucional. Segundo, são de caráter privado. Terceiro, não geram dividendos ou lucros. Quarto, têm autonomia e controle das suas atividades. Quinto, podem usufruir da participação de trabalho voluntário (Salamon e Anheier, 1999). Portanto, a finalidade do terceiro setor é produzir um dado bem ou serviço, mas não existe uma intenção explícita de enriquecimento ou de distribuição de lucros para quem integra esse tipo de associações, mutualidades ou cooperativas. Finalmente, o terceiro setor depende muito da cultura e história do país em que emerge. Países que já tiveram oportunidade de atingir um relativo desenvolvimento econômico, no quadro da racionalidade ins trumental do capitalismo.

O ponto de partida crucial que deu origem ao terceiro setor situa-se no contexto do processo histórico de industrialização e de urbanização das sociedades capitalistas mais desenvolvidas, no século XIX. Neste domínio, devemos ter presente a natureza da crise da trajetória histórica do Estado e do mercado a partir de meados do século XIX na Europa ocidental e nos EUA. De fato, nesse período histórico o Estado era completamente omisso em relação a políticas sociais que poderiam adequar-se à dimensão das necessidades econômicas e sociais da grande massa de trabalhadores assalariados prevenção das doenças, dos acidentes de trabalho, do desemprego, da miséria na velhice. Por outro lado, a escola pública era quase inexistente nos diferentes níveis de ensino. Se associarmos a esta realidade os salários baixos, as condições de trabalho paupérrimas, os horários de trabalho extenuantes e a inexistência de direitos e práticas sindicais nas empresas de então, não admira que as reivindicações e as alternativas da grande massa de trabalhadores assalariados começassem a estruturar-se no sentido de um movimento associativo extenso e diferenciado.

Para chegarmos a essa conclusão, basta analisar as associações de socorros mútuos, caixas econômicas, mutualidades, cooperativas e seguros que emergiram a partir de meados do século XIX na Europa ocidental e nos EUA. De fato, em termos dos seus princípios básicos, eram organizações 


\section{FÓRUM - SOCIOLOGIA ECONÔMICA \\ ATUALIDADE DA CONSTRUÇÃO DO OBJETO CIENTÍFICO DA SOCIOLOGIA ECONÔMICA \\ José Maria Carvalho Ferreira}

criadas fundamentalmente pelo operariado. Os seus objetivos e interesses mesclavam-se através da criação de estruturas de solidariedade e de segurança social, de modo a amenizar as suas condições de vida, econômicas e sociais marcadas por um patronato despótico e discricionário e um Estado omisso na concretização prática de políticas sociais (Goodolphim, 1974; Gide, 1905; Hall, 1987).

Em determinadas circunstâncias, na inexistência de sindicatos e partidos, identificados com os interesses e objetivos do operariado de então, essas organizações tinham finalidades que se orientavam no sentido da estruturação de alternativas societárias opostas à lógica do mercado capitalista e do Estado (Costa, 1986; Desroche, 1983). Seu funcionamento também merece ser comentado: o espaçotempo do processo de tomada de decisão desse tipo de organizações, geralmente, estava polarizado na Assembléia-Geral, permitindo assim que as tipologias de autogestão, de participação e de motivação dos associados tivessem uma tradução prática no funcionamento interno dessas organizações.

Como primeira aproximação conceitual do que hoje é convencional caracterizar como terceiro setor, não podemos prescindir destes ensinamentos, que tiveram grande expressividade social no século XIX na Europa e também em outros países capitalistas mais desenvolvidos, como os EUA. Entretanto, durante o século XX, a sociedade capitalista e o Estado evoluíram no sentido do desenvolvimento e do crescimento econômico, integrando grande parte das reivindicações dessas organizações na lógica normativa do mercado e das políticas sociais do Estado-Providência.

Não admira, assim, que muitas das cooperativas e mutualidades que integravam o terceiro setor tenham sido objeto de uma grande descaracterização, em relação aos princípios e práticas que estiveram na sua origem, no século XIX. Quer no modelo organizacional, em termos de divisão do trabalho, estrutura hierárquica formal, processo de tomada de decisão e processo de liderança, quer nas formas e conteúdos em que os lucros são distribuídos, muitas das cooperativas, das mutualidades e até associações que integram o terceiro setor seguem os ditames da racionalidade instrumental do capitalismo.

Hoje, como já referimos, em função da natureza da crise do Estado e do mercado, o terceiro setor tem, no entanto, potencialidades específicas que o distanciam da lógica burocrática e centralista do Estado e das contingências da maximização do lucro, desenvolvidas pela iniciativa capitalista privada. Evoluindo no sentido da produção, distribuição, troca e consumo de bens e serviços de proximidade, incrustados em relações sociais e relações pessoais atravessadas pela solidariedade, pelo apoio mútuo e a reciprocidade, torna-se possível criar uma identidade coletiva entre os que trabalham nas organizações do terceiro setor, entre produtores e consumidores, de tal forma que as relações informais e o interconhecimento possam criar redes sociais condizentes com o desenvolvimento local e 


\section{FÓRUM - SOCIOLOGIA ECONÔMICA \\ ATUALIDADE DA CONSTRUÇÃO DO OBJETO CIENTÍFICO DA SOCIOLOGIA ECONÔMICA \\ José Maria Carvalho Ferreira}

comunitário (Laville, 2000).

Várias razões estão na origem da probabilidade de um desenvolvimento exponencial do terceiro setor nas sociedades contemporâneas. Em primeiro lugar, mantendo-se a situação estrutural e institucional de desemprego e de precariedade de vinculação contratual, com contratos de trabalho parciais, temporários, sazonais ou atípicos, como solução de sobrevivência econômica e social, os trabalhadores assalariados que não queiram engrossar o mundo da economia informal serão forçados a evoluir para um tipo de emprego e de contrato de trabalho que lhes permita maior estabilidade econômica, social, política e cultural e, logicamente, uma identidade organizacional que não têm.

No contexto da multidimensionalidade das organizações emergentes do terceiro setor cooperativas, associações privadas sem fins lucrativos, fundações ou mutualidades -, uma parte delas integra-se em um tipo de atividades econômicas denominadas de Economia Social, como é o caso em países como a França, Bélgica, Portugal, Canadá e Espanha (Defourny e Monzon, 1992). Ou então são denominadas pelo conceito genérico de Organizações sem Fins Lucrativos ou de Trabalho Social (James, 1987; Powell, 1987), como ocorre nos países anglo-saxônicos e nos países escandinavos. Como denominador comum, todas elas são de natureza privada, não têm como objetivo o lucro, baseiam o seu modo de funcionamento na solidariedade, no apoio mútuo e na reciprocidade e, em última instância, são uma possibilidade plausível e lógica de arranjar trabalho e manter o emprego de uma forma contínua e estável.

Em segundo lugar, o Estado não consegue dinamizar um conjunto de políticas sociais conseqüentes para erradicar os problemas que afetam a vida quotidiana das famílias e das comunidades locais, que integram a sociedade civil, nos domínios da segurança, do crime, da droga, da violência, da pobreza e da miséria. Todos estes fatores, sem exceção, geram a exclusão social e fenômenos sociais desviantes com incidências negativas na coesão social e na ordem social.

Desse conjunto de problemas surgem novas necessidades de índole social, política e cultural. São bens e serviços que se baseiam na crise de identidade social, cultural e política. Os indivíduos e grupos que constituem a sociedade civil perderam a sua vocação de produção de sociabilidade e de sentido identitário. Não sendo o Estado e o mercado as estruturas e as instituições com capacidade para esse efeito, as organizações do terceiro setor emergem como uma solução plausível.

Os bens e serviços que estão integrados no terceiro setor tanto podem atuar em serviços de proximidade - apoio à velhice; animação cultural e social - como ser dirigidos a jovens ou a serviços de formação e de educação - jardins de infância e escolas de formação (Laville, 2000). Outros bens e serviços estão articulados com o controle e a integração social, como os que são decorrentes de 


\section{FÓRUM - SOCIOLOGIA ECONÔMICA \\ ATUALIDADE DA CONSTRUÇÃO DO OBJETO CIENTÍFICO DA SOCIOLOGIA ECONÔMICA \\ José Maria Carvalho Ferreira}

fenômenos desviantes e da marginalidade social, sendo desenvolvida uma série de serviços sociais, de animação cultural e social. Outros ainda estão diretamente relacionados com a saúde, a educação e a formação; outros, com o desenvolvimento local ou com os direitos humanos, com a habitação, com a defesa do ambiente; há, ainda, os bens e serviços dos setores agrícola, industrial e comercial.

Grande parte dessas atividades são subsidiadas pelo Estado ou por fundações privadas, na medida em que muitas delas têm extrema dificuldade em manter um equilíbrio financeiro com base nos custos de funcionamento corrente e as receitas geradas com a venda dos serviços à comunidade e à sociedade civil (Salamon e Anheier, 1999). Todavia, esta simbiose de interesses e objetivos entre o Estado, a iniciativa privada e o terceiro setor é produto das interdependências e complementaridades geradas entre eles. O desvio assume formas cada vez mais perversas e com enormes custos para o Estado e para a sociedade civil.

Não admira, assim, que, perante a evidente incapacidade do Estado e do mercado em regularem e controlarem eficazmente essa realidade, o Estado e as fundações privadas sejam levados a financiar todo o tipo de atividades que possam potencialmente diminuir os custos econômicos e sociais provocados pelos desviantes. Na verdade, perante os enormes custos resultantes da necessidade de integração e de controle do desvio, se o Estado e o mercado não fossem auxiliados pelas atividades do terceiro setor, os custos financeiros na criação e manutenção de hospitais psiquiátricos, prisões, forças policiais e militares, e tribunais, tornar-se-iam incomportáveis para qualquer sociedade.

É preciso mencionar ainda outras tendências do terceiro setor, que decorrem das suas potencialidades enquanto possibilidade alternativa aos modelos de sociedade vigentes. Em algumas organizações do terceiro setor, a função do fator de produção trabalho relacionada às atividades de produção, distribuição, troca e consumo de bens e serviços, na medida em que resulta de uma contingência de adaptação e de reação à crise de regulação e de controle do Estado e do mercado, segue os ditames da racionalidade instrumental do capitalismo, ou seja: depende dos mesmos conteúdos e das mesmas formas de divisão do trabalho, da mesma autoridade hierárquica formal, do mesmo processo de tomada de decisão e do mesmo processo de liderança. Nessas condições, torna-se o fator essencial de maximização do lucro.

Além de mencionar a evolução normativa do terceiro setor, precisamos também fazer menção às teorias e práticas que pretendem transformar-se em uma alternativa crível ao modelo econômico desenvolvido pelo capitalismo e o pelo Estado, sobretudo as que têm uma incidência analítica no cooperativismo, na economia solidária, na economia popular ou na economia social. Os pressupostos alternativos baseiam-se em três grandes opções: primeira, na extinção das lógicas concorrenciais e 


\section{FÓRUM - SOCIOLOGIA ECONÔMICA \\ ATUALIDADE DA CONSTRUÇÃO DO OBJETO CIENTÍFICO DA SOCIOLOGIA ECONÔMICA \\ José Maria Carvalho Ferreira}

competitivas que têm como finalidade a maximização do lucro; segunda, na extinção das estruturas hierárquicas de autoridade formal, de modo a que a execução de tarefas e funções e o processo de tomada de decisão sejam baseados em uma participação democrática e autogestionária; terceira, no fim da oposição entre produtores e consumidores, introduzindo relações de identidade generalizada entre os processos de produção, de troca, de distribuição e consumo de bens e serviços. A identidade entre produtores e consumidores é possível, desde que as suas relações estejam incorporadas em uma rede social baseada numa solidariedade e reciprocidade sistemáticas.

Todavia, para que um projeto utópico baseado no terceiro setor tenha um sentido histórico, com alguma continuidade e plausibilidade, é preciso atentar para a necessidade de criar redes sociais de tipo formal e informal em nível local, regional, nacional e mundial, de tal forma que a produção, distribuição, troca e consumo de bens e serviços sejam baseados em relações sociais e relações interpessoais, cuja coordenação e controle decorram da "democracia direta". Por outro lado, persiste a necessid ade de uma mudança na atual organização do trabalho. Esta passaria, inexoravelmente, pela extinção da divisão do trabalho e da autoridade hierárquica formal, assim como das modalidades de acesso à informação, ao conhecimento e à energia envolvidos no processo de tomada de decisão e no processo de liderança. Deste modo, poderíamos pensar na possibilidade de uma autogestão generalizada no terceiro setor, base a partir da qual a liberdade, a solidariedade, a cooperação, o apoio mútuo e a reciprocidade se tornariam os sustentáculos da democracia direta.

\section{CONCLUSÃO}

Ao final deste artigo, gostaríamos de recapitular quatro de suas principais implicações. Em primeiro lugar, qualquer atualização do objeto científico da sociologia econômica passa, necessariamente, pela plasticidade social da organização do trabalho, ou seja, de todos os fatores institucionais e estruturais a ela associados. O espaço-tempo da divisão do trabalho, a autoridade hierárquica formal, o processo de tomada de decisão e o processo de liderança fornecem-nos a epistemologia e a metodologia crucial para esse efeito. É um espaço-tempo inscrito nas atividades econômicas e sociais associadas à produção, distribuição, troca e consumo de bens e serviços.

Em segundo lugar, os modelos e os paradigmas científicos que foram fundamentais para prevenir e controlar o processo histórico de urbanização e de industrialização das sociedades capitalistas mais desenvolvidas, hoje, revelam-se ineficientes. De fato, com o advento histórico das 


\section{FÓRUM - SOCIOLOGIA ECONÔMICA \\ ATUALIDADE DA CONSTRUÇÃO DO OBJETO CIENTÍFICO DA SOCIOLOGIA ECONÔMICA \\ José Maria Carvalho Ferreira}

TIC's e as contingências da globalização, as atividades econômicas e sociais dizem cada vez mais respeito a modalidades de produção, distribuição, troca e consumo de bens e serviços com características analítico-simbólicas. A coincidência do tempo virtual com o tempo real acaba com as vicissitudes temporais do curto, médio e longo prazo das atividades econômicas e sociais clássicas.

Em terceiro lugar, o tempo histórico da racionalidade instrumental do capitalismo exige qualificações e competências ao fator de produção trabalho que não se coadunam mais com os perfis profissionais-padrão da segunda revolução industrial, baseados no setor automotivo, químico, sederúrgico, têxtil, de cimento e vidro. As exigências comunicacionais e afetivas perpassam as qualificações e as competências de todos os perfis profissionais ligados à produção, distribuição, troca e consumo de bens e serviços analítico-simbólicos. Só para estes existem possibilidades de emprego e de vinculação contratual no mercado de trabalho.

Finalmente, o terceiro setor, enquanto probabilidade sociohistórica, pode desenvolver-se como alternativa societária à crise do capitalismo e do Estado e, por outro lado, é sem dúvida alguma um dos fatores capazes de alavancar a construção e o desenvolvimento do objeto científico da sociologia econômica nas sociedades contemporâneas.

\section{REFERÊNCIAS}

BILLIARD, I.; DEBORDEAUX, D. ; LUROL, M. (Eds.). Vivre la précarité - trajectoires et projects de vie. Paris: Ed. L'aube, 2000.

BOYER, R. La théorie de la régulation: une analyse critique. Paris: La Découverte, 1986.

BRAVERMAN, H. Trabalho e capital monopolista. A degradação do trabalho no século XX. Rio de Janeiro: Zahar, 1977.

BROCK, D. ; VETTER, H. R.. L'érosion biographique comme conséquence des bouleversements technologiques. Exemple de l'introduction des techniques nouvelles dans l'imprimerie en RFA. Sociologie du Travail, n. 2, p. 125-143, 1986.

CASTEL, R. Centralité du travail et cohésion sociale. In: KERGOAT et al. Le Monde du Travail. Paris, 


\section{FÓRUM - SOCIOLOGIA ECONÔMICA \\ ATUALIDADE DA CONSTRUÇÃO DO OBJETO CIENTÍFICO DA SOCIOLOGIA ECONÔMICA \\ José Maria Carvalho Ferreira}

La Découverte, 1998. p. 50-60.

CAVESTRO, W. Automatisation, organisation du travail et qualification dans les PME: Le cas des machines-outils à commande numérique. Sociologie du Travail, n. 4, p. 434- 446, 1984.

COSTA, F. F. As cooperativas e a economia social. Lisboa: Livros Horizonte, 1986.

DEFOURNY, J. ; MONZÓN C. J. (Eds.). Économie social. Bruxelles: CIRIEC/De Boeck Université, 1992.

DESROCHE, H. Pour un traité d'économie sociale. Paris: CIEM, 1983.

DUBAR, C. Les identités professionnelles. In: KERGOAT et al. Le Monde du Travail. Paris: La Découverte, 1998. p. 66-74.

DURKHEIM, E. A divisão do trabalho social. v. 2, 3. ed. Lisboa: Editorial Presença, 1991.

FERREIRA, J. M. C. et al. Manual de psicossociologia das organizações. Alfragide: McGraw-Hill, 2001.

GIDE, C. Èconomie sociale. Paris: Sirey, 1905.

GOLDFINGER, C. Travail et hors-travail - vers une société fluide. Paris: Editions Odile Jacob, 1998.

GOODOLPHIM, C. A associação - história e desenvolvimento das associações portuguesas. Lisboa:

Livros Horizonte, 1974.

GRANOVETTER, M. Economic action and social structure: the problem of embeddedness. American Journal of Sociology, v. 91, n. 3, p. 481-510, nov. 1985.

GROZELIER, A. M. Pour en finir avec la fin du travail. Paris: Les Editions de l'Atelier, 1998. 


\section{FÓRUM - SOCIOLOGIA ECONÔMICA \\ ATUALIDADE DA CONSTRUÇÃO DO OBJETO CIENTÍFICO DA SOCIOLOGIA ECONÔMICA \\ José Maria Carvalho Ferreira}

HALL, P. D. A historical overview of the private non-profit setor. In: POWELL, W. (Ed.). The Nonprofit Setor - a Research Handbook. New Haven and London: Yale University Press, 1987.

JAMES, E. The Non-profit Setor in International Perspective. New York/Oxford: Oxford University Press, 1987.

KERN, H.; SCHUMANN, M. El fin de la division del trabajo. Racionalizacion en la produccion industrial. Madrid: Centro de Publicaciones Ministerio de Trabajo y Seguridad Social, 1988.

LALLEMENT, M.; LAVILLE, J. L. Qu'est-ce que le tiers secteur? Associations, économie solidaire, économie sociale. Sociologie du Travail, v. 42, n. 4, p. 523-529, 2002.

LAVILLE, J. L. L’économie solidaire. Paris: Desclée de Brouwer, 2000.

LÈVESQUE, B. et al. La nouvelle sociologie économique. Paris: Desclée de Brouwer, 2001.

MEDA, D. Le travail. Une valeur en voie de disparition. Paris: Aubier, 1995.

PAUGAM, S. Le Salarié de la précarité. Paris: PUF, 2000.

POLANYI, K. La Gran transformación. Madrid: La Piqueta, 1989.

POTTIER, C. La division internationale du travail. In: KERGOAT et al. Le Monde du travail. Paris: La Découverte, 1998. p. 310-318.

POWELL, W. (Ed.). The non-profit setor - a research handbook. New Haven and London: Yale University Press, 1987.

RIFKIN, J. La Fin du travail. Paris: La Découverte, 1996.

ROSANVALLON, P. La Nouvelle question sociale: repenser l'Etat-Providence. Paris: Seuil, 1995. 


\section{FÓRUM - SOCIOLOGIA ECONÔMICA \\ ATUALIDADE DA CONSTRUÇÃO DO OBJETO CIENTÍFICO DA SOCIOLOGIA ECONÔMICA \\ José Maria Carvalho Ferreira}

ROSE, J. Travail et formation. In: KERGOAT et al. Le Monde du travail. Paris, La Découverte, 1998, p. $265-272$.

SALAMON, L.; ANHEIER, H. (Eds.). Global civil society - dimensions of the non-profit setor. Baltimore: The Johns Hopkins Center for Society Studies, 1999.

STEINER, P. La Sociologie économique. Paris: La Découverte, 1999.

SWEDBERG, R. Une histoire de la sociologie économique. Paris: Desclée de Brouwer. 1994.

WEBER, M. Economia y sociedad. México: Fondo de Cultura Econômica, 1994.

\section{Artigo recebido em 11.07.2005. Aprovado em 24.01.2007.}

\section{José Maria Carvalho Ferreira}

Professor catedrático do Instituto Superior de Economia e Gestão da Universidade Técnica de Lisboa. Interesse de pesquisa na área sociologia econômica, psicossociologia das organizações, globalização e movimentos sociais, terceiro setor.

E-mail: jmcf@iseg.utl.pt

Endereço: Rua Miguel Lupi 20, Lisboa - Portugal - 1249-078 